\title{
Electron mobility degradation due to Remote Coulomb scattering in Ge MOSFET
}

\author{
Haoyu Xu, Jing Zhang, Shuhua Wei \\ Microelectronics Department, North China University \\ of Technology \\ Beijing, China \\ jianwansannian@163.com (Haoyu Xu)
}

\author{
Xiaolei Wang, Wenwu Wang \\ Key Laboratory of Microelectronics Devices \& \\ Integrated Technology, Institute of Microelectronics, \\ Chinese Academy of Sciences \\ Beijing, China
}

\begin{abstract}
Remote Coulomb scatterings (RCS) on electron mobility degradation are experimentally investigated in Ge based metal-oxide-semiconductor field-effect-transistor (MOSFETs) with $\mathrm{GeO}_{\mathrm{x}} / \mathrm{Al}_{2} \mathrm{O}_{3}$ gate stacks. The mobility is found increased with thicker $\mathrm{GeO}_{\mathrm{x}}(7.8-20.8 \AA)$. The physical origin of this mobility dependence on $\mathrm{GeO}_{\mathrm{x}}$ thickness is explored. The following factors are excluded: Coulomb scattering due to interfacial traps at $\mathrm{GeO}_{\mathrm{x}} / \mathrm{Ge}$, phonon scattering, and surface roughness scattering. Therefore, the RCS from charges in gate stacks are studied. The charge distributions in $\mathrm{GeO}_{\mathrm{x}} / \mathrm{Al}_{2} \mathrm{O}_{3}$ gate stacks are experimentally evaluated. The bulk charges in $\mathrm{Al}_{2} \mathrm{O}_{3}$ and $\mathrm{GeO}_{\mathrm{x}}$ are found negligible. The density of interfacial charge is $+3.2 \times 10^{12} \mathrm{~cm}^{-2}$ at $\mathrm{GeO}_{\mathrm{x}} / \mathrm{Ge}$ interface, and $-2.3 \times 10^{12} \mathrm{~cm}^{-2}$ at $\mathrm{Al}_{2} \mathrm{O}_{3} / \mathrm{GeO}_{\mathrm{x}}$ interface. The electric dipole at $\mathrm{Al}_{2} \mathrm{O}_{3} / \mathrm{GeO}_{\mathrm{x}}$ interface is found $+0.15 \mathrm{~V}$, corresponding to areal charge density of $1.9 \times 10^{13} \mathrm{~cm}^{-2}$. The origin of this mobility dependence on $\mathrm{GeO}_{\mathrm{x}}$ thickness is attributed to the RCS due to electric dipole at $\mathrm{Al}_{2} \mathrm{O}_{3} / \mathrm{GeO}_{\mathrm{x}}$ interface. And this remote dipole scattering is found to play a significant role on mobility degradation. The discovery of this new scattering mechanism indicates that engineering of $\mathrm{Al}_{2} \mathrm{O}_{3} / \mathrm{GeO}_{\mathrm{x}}$ interface is key for mobility enhancement and device performance improvement. These results are helpful for understanding and engineering the Ge mobility enhancement.
\end{abstract}

Keywords-Ge; Mobility; Remote Coulomb scatterings;

\section{INTRODUCTION}

Ge semiconductor is rather potential as channel material in order to further equivalently scale down the metal-oxidesemiconductor field-effect-transistors (MOSFETs) beyond $10 \mathrm{~nm}$ technology node. ${ }^{[1]-[5]}$ For its successful application, a relevant parameter is effective channel mobility $\mu_{\text {eff }}$, which is key point for Ge in replacement of Si substrate. The peak electron $\mu_{\text {eff }}$ is experimentally found to be $\sim 750 \mathrm{~cm}^{2} / \mathrm{V} \cdot \mathrm{s}$ using $\mathrm{GeO}_{x}$ passivation and $\mathrm{Al}_{2} \mathrm{O}_{3}$ barrier layer, ${ }^{[6], ~[7]}$ which gate structure has been considered as one of the most feasible routes for realizing both low density of interfacial states $\left(D_{\text {it }}\right)$ and low equivalent oxide thickness. ${ }^{[3], ~[4], ~[8], ~[9] ~}$ Furthermore, to maximize the channel on-state current drivability, the scattering mechanisms that limit the $\mu_{\text {eff }}$ are of great concern. Developing a process technology that improves the mobility requires understanding the mechanism of Ge mobility degradation. ${ }^{[10]}$ Several factors have been reported to induce mobility degradation, such as interfacial traps, ${ }^{[11],}{ }^{[12]}$ surface roughness scattering, ${ }^{[7],}{ }^{[13]}$ National Natural Science of China (No. 61176091) and oxygen atoms in Ge substrate. ${ }^{[14]}$ However, the mechanisms of Ge mobility degradation are still not fully clear. Especially the remote Coulomb scatterings (RCS) from Ge gate stacks are not reported to data, even though the RCS is found to play an important role in Si based

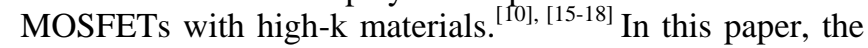
RCS is experimentally investigated for Ge MOSFETs. The RCS from electric dipole at $\mathrm{Al}_{2} \mathrm{O}_{3} / \mathrm{GeO}_{\mathrm{x}}$ interface is found to play a significant role on electron mobility degradation. This remote dipole scattering (RDS) indicates that the $\mathrm{Al}_{2} \mathrm{O}_{3} / \mathrm{GeO}_{\mathrm{x}}$ interface is critical for device performance enhancement.

\section{EXPERIMENTAL}

The Ge MOSFETs were fabricated as follows. The starting substrate is homemade $2 \mu \mathrm{m}$ thick p-doped (100) epitaxial Ge on 8 inch p-doped (100) Si. The doping concentration is $\sim 3 \times 10^{17} \mathrm{~cm}^{-3}$ for epitaxial Ge. After the cleaning of $\mathrm{Ge}$ surface by 100:1 $\mathrm{H}_{2} \mathrm{O}: \mathrm{HF}$ for $60 \mathrm{~s}$, the wafers were immediately capped with low temperature oxide $\mathrm{SiO}_{2}(\sim 80$ $\AA$ ). Then source/drain region was defined and phosphorus ions were implanted using an energy of $15 \mathrm{keV}$ and a dose of $10^{15} \mathrm{~cm}^{-2}$. The activation annealing was carried out at $600{ }^{\circ} \mathrm{C}$ for $1 \mathrm{~min}$ in $\mathrm{N}_{2}$. Then the gate stacks were formed as follows. The gate region was opened by lithography-defined wet chemical etching, and the exposed Ge surface was again dipped in 100:1 $\mathrm{H}_{2} \mathrm{O}: \mathrm{HF}$ for $60 \mathrm{~s}$. After that the Ge surface was immediately subjected to remote oxygen plasma oxidation to form $\mathrm{GeO}_{\mathrm{x}}$. Subsequently, $\mathrm{Al}_{2} \mathrm{O}_{3}$ was deposited by atomic layer deposition (ALD) using TMA and $\mathrm{H}_{2} \mathrm{O}$ as precursors at $300^{\circ} \mathrm{C}$. Then post deposition annealing (PDA) was performed at $400{ }^{\circ} \mathrm{C}$ in $\mathrm{N}_{2}$ for $5 \mathrm{~min}$, followed by the ALD deposition of $3 \mathrm{~nm}$ TiN and $75 \mathrm{~nm}$ W. After that, Ti source/drain contact and Al back contact were formed. Finally the wafers were subjected to the forming gas annealing at $400^{\circ} \mathrm{C}$ in $5 \% \mathrm{H}_{2} / 95 \% \mathrm{~N}_{2}$ for $30 \mathrm{~min}$. In addition, the MOS capacitors with $\mathrm{Ge} / \mathrm{GeO}_{\mathrm{x}} / \mathrm{Al}_{2} \mathrm{O}_{3} / \mathrm{TiN} / \mathrm{W}$ gate stacks were also fabricated with the same process conditions with Ge MOSFETs.

\section{RESULTS AND DISCUSSION}

\section{A. Mobility for different $\mathrm{GeO}_{x}$ thicknesses}

In order to investigate the remote Coulomb scattering, the mobility is evaluated as a function of the interfacial 
$\mathrm{GeO}_{\mathrm{x}}$ thickness. Figure 1 shows the $\mathrm{I}_{\mathrm{d}}-\mathrm{V}_{\mathrm{g}}$ characteristics of Ge nMOSFETs and electron mobility evaluated by the split capacitance-voltage $(\mathrm{C}-\mathrm{V})$ method at room temperature. Here four different thicknesses of $\mathrm{GeO}_{\mathrm{x}}$ interlayers were grown. From the Fig. 1(b), it can be seen that the mobility $\mu_{\text {eff }}$ at low inversion carrier density $\left(\mathrm{N}_{\mathrm{s}}\right)$ increases with thicker $\mathrm{GeO}_{\mathrm{x}}$. The mobility in our experiments is lower than bulk Ge substrate, because of the crystal quality of the epitaxial Ge. ${ }^{[19]}$ However, all the samples were fabricated using same epitaxial Ge. As a result, this mobility dependence on $\mathrm{GeO}_{\mathrm{x}}$ thickness is also available. It should be stated that the series resistance due to source/drain is experimentally determined to be negligible for $100 \mu \mathrm{m}$ gate length (less than 3\%), by using MOSFETs with different gate lengths (not shown here).

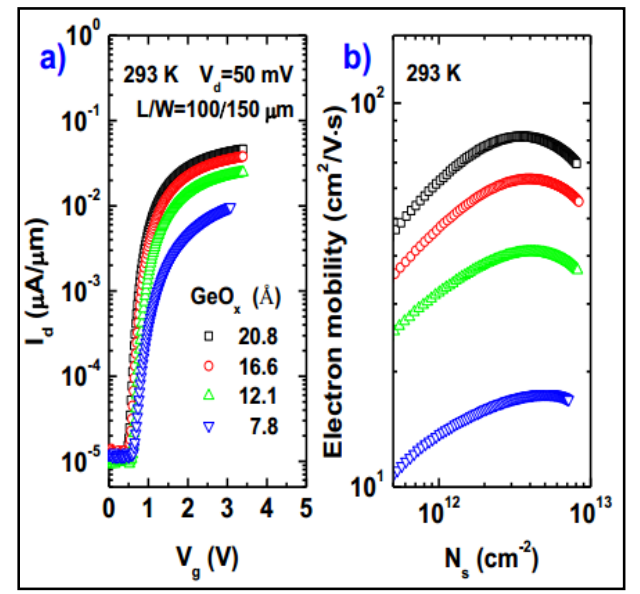

FIG. 1. (a) $\mathrm{I}_{\mathrm{d}}-\mathrm{V}_{\mathrm{g}}$ of $\mathrm{Ge}$ nMOSFETs with $\mathrm{Ge} / \mathrm{GeO}_{\mathrm{x}} / \mathrm{Al}_{2} \mathrm{O}_{3} / \mathrm{TiN} / \mathrm{W}$ gate stacks at room temperature. The $\mathrm{Al}_{2} \mathrm{O}_{3}$ thickness is $10 \mathrm{~nm}$. The $\mathrm{GeO}_{\mathrm{x}}$ thickness is given in the figure. (b) Electron mobility for different $\mathrm{GeO}_{\mathrm{x}}$ thicknesses.

\section{B. Exclusion of $D_{i t}$ as origin}

In order to understand this phenomenon, the $D_{i t}$ is firstly evaluated for the four samples. Fig. 2 shows the $\mathrm{C}-\mathrm{V}$ curves of $\mathrm{Ge} / \mathrm{GeO}_{\mathrm{x}} / \mathrm{Al}_{2} \mathrm{O}_{3} / \mathrm{TiN} / \mathrm{W}$ MOS capacitors at $200 \mathrm{~K}$ and $100 \mathrm{~K}$ for $7.8 \AA \mathrm{GeOx}$. The superior $\mathrm{C}-\mathrm{V}$ characteristics are observed. Then the $D_{\text {it }}$ are extracted by the low temperature conductance method for different $\mathrm{GeO}_{\mathrm{x}}$ thicknesses as shown in the Fig. 2(c). It can be seen that the $\mathrm{D}_{\text {it }}$ are nearly identical for different $\mathrm{GeO}_{\mathrm{x}}$ thicknesses. This is consistent with published reports that the $D_{i t}$ is nearly unchanged when $\mathrm{GeO}_{\mathrm{x}}$ thickness is larger than $\sim 7 \AA^{[20],[21]}$ Thus the $D_{\text {it }}$ can be excluded as physical origin of mobility dependence on $\mathrm{GeO}_{\mathrm{x}}$ thickness.

\section{Exclusion of remote phonon scattering as origin}

Secondly the remote phonon scattering is considered. Fig. 3 shows the $I_{d}-V_{g}$ characteristics and electron mobility at $77 \mathrm{~K}$. It can be seen that the $\mu_{\text {eff }}$ still increases with thicker $\mathrm{GeO}_{\mathrm{x}}$. Considering that the phonon scattering can be ignored at $77 \mathrm{~K},{ }^{[22]}$ the remote phonon scattering can also be ruled out.

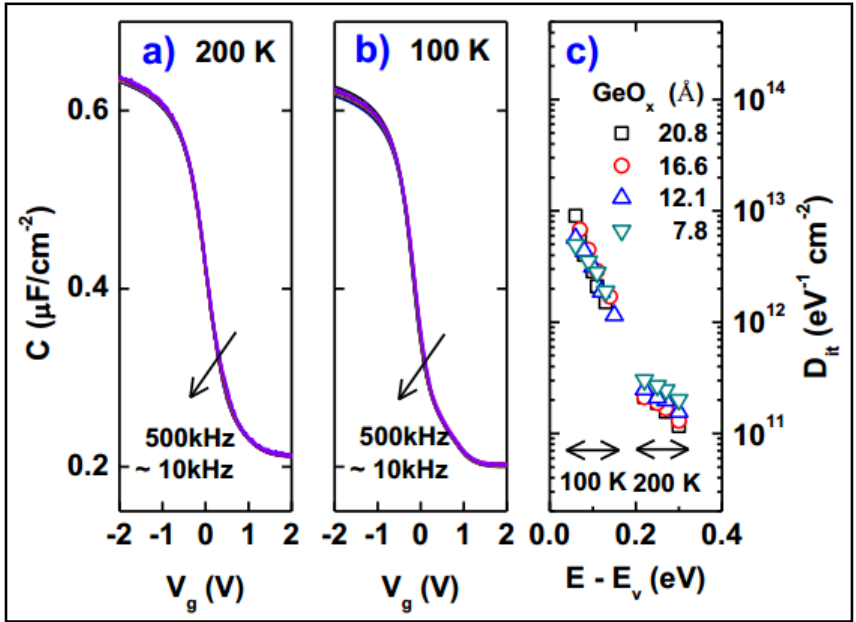

FIG. 2. C-V curves of $\mathrm{Ge} / \mathrm{GeO}_{\mathrm{x}} / \mathrm{Al}_{2} \mathrm{O}_{3} / \mathrm{TiN} / \mathrm{W}$ MOS capacitors at (a) $200 \mathrm{~K}$ and (b) $100 \mathrm{~K}$ for $7.8 \AA \mathrm{GeO}_{\mathrm{x}}$. The $\mathrm{D}_{\mathrm{it}}$ is given in Fig. 2(c) for different $\mathrm{GeO}_{\mathrm{x}}$ thicknesses.

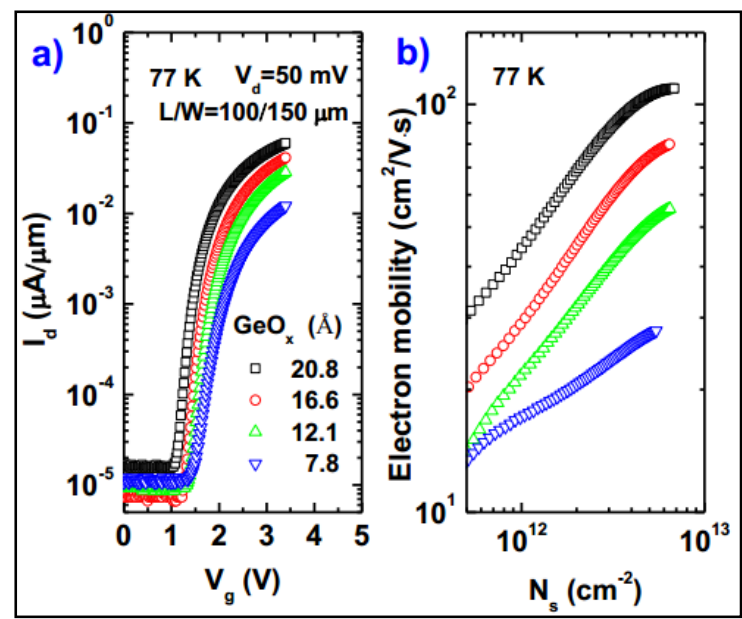

FIG. 3. (a) $\mathrm{I}_{d}-\mathrm{V}_{\mathrm{g}}$ and (b) electron mobility at $77 \mathrm{~K}$.

\section{Exclusion of surface roughness scattering as origin}

Thirdly the surface roughness scattering is studied. The root mean square (rms) of surface roughness is experimentally determined to beidentical $(\sim 0.3 \mathrm{~nm})$ for different $\mathrm{GeO}_{\mathrm{x}}$ thicknesses by atomic force microscope (AFM) (not shown here). Furthermore, the $\mu_{\text {eff }}$ at low $N_{s}$ is mainly due to the Coulomb scattering but not surface roughness scattering. ${ }^{[23]}$ Consequently, the surface roughness scattering cannot account for this mobility dependence on $\mathrm{GeO}_{\mathrm{x}}$ thickness.

\section{E. Charge distribution in $\mathrm{GeO}_{x} / \mathrm{Al}_{2} \mathrm{O}_{3}$ gate stacks}

Based on the above discussion, there is another scattering mechanism, and we consider the RCS as the possible origin. In order to further investigate the RCS, the charge distribution in the $\mathrm{Al}_{2} \mathrm{O}_{3} / \mathrm{GeO}_{\mathrm{x}} / \mathrm{Ge}$ gate stacks is necessary to obtain. In our previous work, we experimentally extracted the charge distribution in Si gate stacks with high-k dielectric. ${ }^{[24]}$ Similarly, the charge distribution in the $\mathrm{Al}_{2} \mathrm{O}_{3} / \mathrm{GeO}_{\mathrm{x}} / \mathrm{Ge}$ gate stacks can be extracted as follows. The flatband voltage $\left(\mathrm{V}_{\mathrm{FB}}\right)$ of 
$\mathrm{TiN} / \mathrm{Al}_{2} \mathrm{O}_{3} /$ terraced-GeO $\mathrm{x}_{\mathrm{x}} / \mathrm{Ge}$ MOS capacitor is given as ${ }^{[24] \text {, }}$ [25]

$$
\begin{aligned}
V_{F B}= & -\frac{Q_{1}}{\varepsilon_{0} \varepsilon_{r}} E O T-\frac{\varepsilon_{1} \rho_{1}}{2 \varepsilon_{0} \varepsilon_{r}^{2}} E O T^{2} \\
& -\frac{Q_{2}}{\varepsilon_{0} \varepsilon_{r}} E O T_{2}+\frac{\left(\varepsilon_{1} \rho_{1}-\varepsilon_{2} \rho_{2}\right)}{2 \varepsilon_{0} \varepsilon_{r}^{2}} E^{2} O T_{2}^{2}+\Delta+\varphi_{m s}
\end{aligned}
$$

where $\mathrm{Q}_{1}$ and $\mathrm{Q}_{2}$ are areal charge densities at $\mathrm{GeO}_{\mathrm{x}} / \mathrm{Ge}$ and $\mathrm{Al}_{2} \mathrm{O}_{3} / \mathrm{GeO}_{\mathrm{x}}$ interfaces, respectively. The $\rho_{1}$ and $\rho_{2}$ are bulk charge densities in $\mathrm{GeO}_{\mathrm{x}}$ and $\mathrm{Al}_{2} \mathrm{O}_{3}$, respectively. The $\varepsilon_{0}, \varepsilon_{\mathrm{r}}$, $\varepsilon_{1}$ and $\varepsilon_{2}$ are vacuum permittivity, relative permittivities of $\mathrm{SiO}_{2}, \mathrm{GeO}_{\mathrm{x}}$ and $\mathrm{Al}_{2} \mathrm{O}_{3}$, respectively. The EOT is equivalent oxide thickness of whole gate stacks, and EOT2 is equivalent oxide thickness of $\mathrm{Al}_{2} \mathrm{O}_{3}$ dielectric. The $\Delta$ is $\mathrm{V}_{\mathrm{FB}}$ shift due to electric dipole at $\mathrm{Al}_{2} \mathrm{O}_{3} / \mathrm{GeO}_{\mathrm{x}}$ interface. A positive dipole is defined when positive charges appear at $\mathrm{Al}_{2} \mathrm{O}_{3}$ side and equivalent negative charges at $\mathrm{GeO}_{\mathrm{x}}$ side. The $\Phi_{\mathrm{ms}}$ is the vacuum workfunction difference between TiN and Ge substrate. The Eq. (1) shows that the $\mathrm{V}_{\mathrm{FB}}$ is a quadratic function of EOT. And the $Q_{1}$ and $\rho_{1}$ can be extracted from the linear and quadratic terms of $\mathrm{V}_{\mathrm{FB}} \mathrm{vs}$. EOT plot. Fig. 4(a) shows the $\mathrm{V}_{\mathrm{FB}}$-EOT plot of TiN/10nm$\mathrm{Al}_{2} \mathrm{O}_{3} /$ terraced- $\mathrm{GeO}_{\mathrm{x}} / \mathrm{Ge}$ MOS capacitors at room temperature. It can be seen that a well linear fitting is obtained for $\mathrm{V}_{\mathrm{FB}}$-EOT curve. Then the interfacial charges at $\mathrm{GeO}_{\mathrm{x}} / \mathrm{Ge}$ interface $\left(\mathrm{Q}_{1}\right)$ can be determined to be $+3.2 \times 10^{12}$ $\mathrm{cm}^{-2}$. And the bulk charges in $\mathrm{GeO}_{\mathrm{x}}\left(\rho_{1}\right)$ can be negligible, indicating well quality of $\mathrm{GeO}_{\mathrm{x}}$ by plasma oxidation. The $\varepsilon_{1}$ is calculated to be 5.1 from Fig. 4(b), which is consistent with the reported results. ${ }^{[26]}$

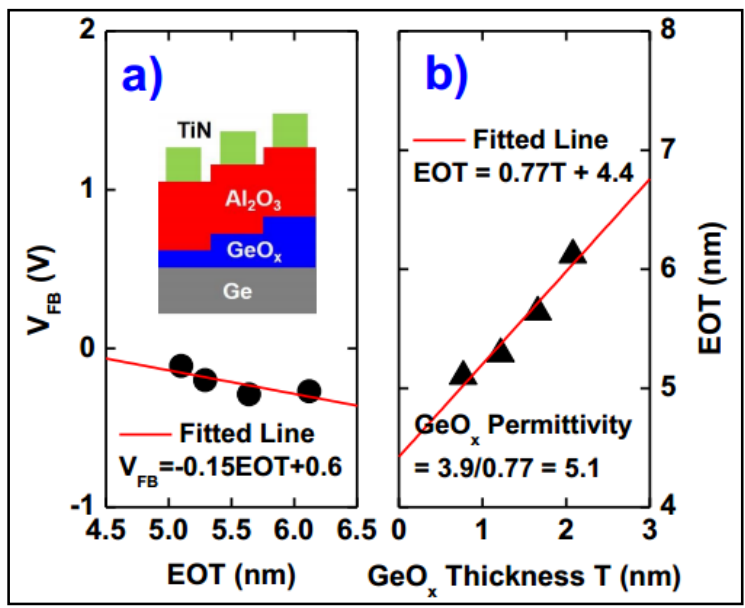

FIG. 4. (a) $\mathrm{V}_{\mathrm{FB}}$ Vs. EOT plot of TiN/10nm- $\mathrm{Al}_{2} \mathrm{O}_{3} /$ terraced-GeO $\mathrm{G}_{\mathrm{x}} / \mathrm{Ge} \mathrm{MOS}$ capacitors at $500 \mathrm{kHz}$. (b) EOT vs. $\mathrm{GeO}_{\mathrm{x}}$ thickness of TiN/10nm$\mathrm{Al}_{2} \mathrm{O}_{3} /$ terraced- $\mathrm{GeO}_{\mathrm{x}} / \mathrm{Ge}$ MOS capacitors.

In addition, The $\mathrm{V}_{\mathrm{FB}}$ of TiN/terraced- $\mathrm{Al}_{2} \mathrm{O}_{3} / \mathrm{GeO}_{\mathrm{x}} / \mathrm{Ge}$ MOS capacitor is given as ${ }^{[24]}$

$$
\begin{aligned}
V_{F B}= & -\frac{Q_{1}+Q_{2}}{\varepsilon_{0} \varepsilon_{r}} E O T+\frac{\varepsilon_{2} \rho_{2} E O T_{1}}{\varepsilon_{0} \varepsilon_{r}^{2}} E O T \\
& -\frac{\varepsilon_{2} \rho_{2}}{2 \varepsilon_{0} \varepsilon_{r}^{2}} E O T^{2}+\frac{Q_{2} E O T_{1}}{\varepsilon_{0} \varepsilon_{r}}-\frac{\varepsilon_{2} \rho_{2}}{2 \varepsilon_{0} \varepsilon_{r}^{2}} E O T_{1}^{2}+\Delta+\varphi_{m s}
\end{aligned}
$$

here the $\mathrm{EOT}_{1}$ is equivalent oxide thickness of $\mathrm{GeO}_{\mathrm{x}}$. Fig. 5(a) shows the $\mathrm{V}_{\mathrm{FB}}$-EOT plot of TiN/terraced- $\mathrm{Al}_{2} \mathrm{O}_{3} / 20.8 \AA$ $\mathrm{GeO}_{\mathrm{x}} / \mathrm{Ge}$ MOS capacitors at room temperature.

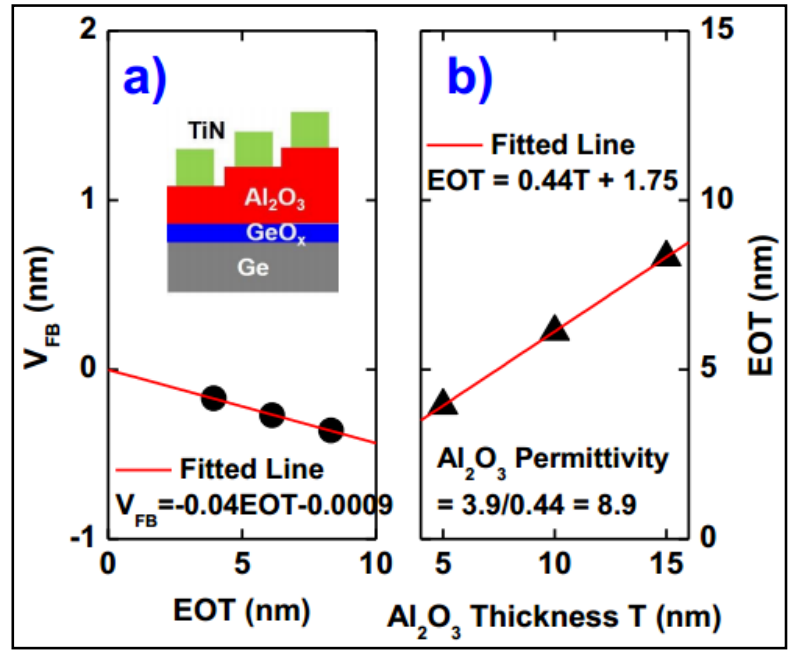

FIG. 5. (a) $\mathrm{V}_{\mathrm{FB}}$ vs. EOT plot of TiN/terraced- $\mathrm{Al}_{2} \mathrm{O}_{3} / 20.8 \AA-\mathrm{GeO}_{\mathrm{x}} / \mathrm{Ge} \mathrm{MOS}$ capacitors at $500 \mathrm{kHz}$. (b) EOT vs. $\mathrm{Al}_{2} \mathrm{O}_{3}$ thickness of TiN/terraced$\mathrm{Al}_{2} \mathrm{O}_{3} / 20.8 \AA-\mathrm{GeO}_{\mathrm{x}} / \mathrm{Ge}$ MOS capacitors.

It can be seen that the a well linear fitted line can be obtained. Comparing the fitting result with the Eq. (2), the bulk charges $\rho_{2}$ in ALD $\mathrm{Al}_{2} \mathrm{O}_{3}$ can be determined to be 0 $\mathrm{cm}_{-3}$. From the linear term in Eq. (2), the interfacial charges at $\mathrm{Al}_{2} \mathrm{O}_{3} / \mathrm{GeO}_{\mathrm{x}}$ interface $\left(\mathrm{Q}_{2}\right)$ can be determined to be $2.3 \times 10^{12} \mathrm{~cm}^{-2}$. The $\varepsilon_{2}$ is calculated to be 8.9 from Fig. 5(b). The dipole $\Delta$ is evaluated as follows. From Eq. (2) the intercept of $\mathrm{V}_{\mathrm{FB}}$-EOT plot is given as

$$
\text { Intercept }=\frac{Q_{2} E_{1} O T_{1}}{\varepsilon_{0} \varepsilon_{r}}+\Delta+\varphi_{m s}
$$

Then the $\Delta$ can be obtained if the intercept, $\mathrm{EOT}_{1}$ and $\Phi_{\mathrm{ms}}$ are known. The intercept is $-0.0009 \mathrm{~V}$ from the Fig. 5(a). The $\mathrm{EOT}_{1}$ is $1.75 \mathrm{~nm}$ from the intercept of EOT vs. $\mathrm{Al}_{2} \mathrm{O}_{3}$ thickness in Fig. 5(b). The vacuum workfunction of TiN has been experimentally determined to be $4.75 \mathrm{eV}$ from TiN/terraced- $\mathrm{SiO}_{2} / \mathrm{Si}$ MOS capacitors (not shown here). Considering the doping concentration in Ge substrate in our experiments, the $\Phi_{\mathrm{ms}}$ can be calculated to be $0.03 \mathrm{eV}$. Then the interfacial dipole at $\mathrm{Al}_{2} \mathrm{O}_{3} / \mathrm{GeO}_{\mathrm{x}}$ interface can be determined to be $+0.15 \mathrm{eV}$. Next, the charge density $\mathrm{Q}_{\Delta}$ that induces this dipole is estimated. The dipole $\Delta$ can be expressed based on Gauss theorem

$$
\Delta=\frac{Q_{\Delta} T_{\Delta}}{\varepsilon_{0} \varepsilon_{\Delta}}
$$

The $\mathrm{T}_{\Delta}$ is inner distance between positive and negative charges of dipole, and is taken as $\sim 0.3 \mathrm{~nm} .{ }^{[27], \text { [28] }}$ The $\varepsilon_{\Delta}$ is relative permittivity of the inner gap in dipole, and is taken as $2 \varepsilon_{1} \varepsilon_{2} /\left(\varepsilon_{1}+\varepsilon_{1}\right)=2 \times 5.7 \times 8.9 /(5.7+8.9)=6.95 .^{[27],[28]}$ Then charge density $\mathrm{Q}_{\Delta}$ is calculated to be $1.9 \times 10^{13} \mathrm{~cm}^{-2}$, which is about one order of magnitude larger than the interfacial charges $\left(\mathrm{Q}_{2}\right)$ at $\mathrm{Al}_{2} \mathrm{O}_{3} / \mathrm{GeO}_{\mathrm{x}}$ interface. 


\section{F. Remote dipole scattering}

The remote Coulomb scattering is discussed. Based on the above results,three types of charges appear in the $\mathrm{Al}_{2} \mathrm{O}_{3} / \mathrm{GeO}_{\mathrm{x}} / \mathrm{Ge}$ gate stacks: interfacial charges at $\mathrm{GeO}_{\mathrm{x}} / \mathrm{Ge}$ interface $\left(\mathrm{Q}_{1}\right)$, interfacial charges at $\mathrm{Al}_{2} \mathrm{O}_{3} / \mathrm{GeO}_{\mathrm{x}}$ interface $\left(\mathrm{Q}_{2}\right)$, and electric dipole at $\mathrm{Al}_{2} \mathrm{O}_{3} / \mathrm{GeO}_{\mathrm{x}}$ interface $(\Delta)$. The $\mathrm{Q}_{1}$ cannot account for the mobility dependence on $\mathrm{GeO}_{\mathrm{x}}$ thickness in Fig. 1(b) and 3(b), because the scattering rate due to $\mathrm{Q}_{1}$ is identical for different $\mathrm{GeO}_{\mathrm{x}}$ thicknesses. The RCS due to $\mathrm{Q}_{2}$ can be negligible compared with RCS due to the $\Delta$, because the $\mathrm{Q}_{2}$ is one order of magnitude smaller than $\mathrm{Q}_{\Delta}$. Furthermore, the scattering rate due to RDS changes as $\exp \left(-2 k_{F} t_{I L}\right)$ with interfacial $\mathrm{GeO}_{\mathrm{x}}$ thickness $t_{I L}$, ${ }^{[29], \text { [30] }}$ where $k_{F}$ is the Fermi wavenumber of the inversion electrons. Therefore, we can conclude that RDS is responsible for the mobility degradation with decreasing the $\mathrm{GeO}_{\mathrm{x}}$ thickness. Considering the exponential dependence of RDS on interlayer $\mathrm{GeO}_{\mathrm{x}}$ thickness, the RDS is a significant contribution of the mobility degradation in the ultrathin EOT region. From Fig. 1(b), the enhancement factor of peak mobility of $20.8 \AA \mathrm{nm} \mathrm{GeO}_{\mathrm{x}}$ against the $12.1 \AA \mathrm{GeOx}$ is around 2. Fig. 6 schematically shows the scattering mechanisms for electron mobility. The RDS significantly reduces the mobility. Therefore, reduction or even elimination of this interfacial dipole should enable us to improve the electron mobility.

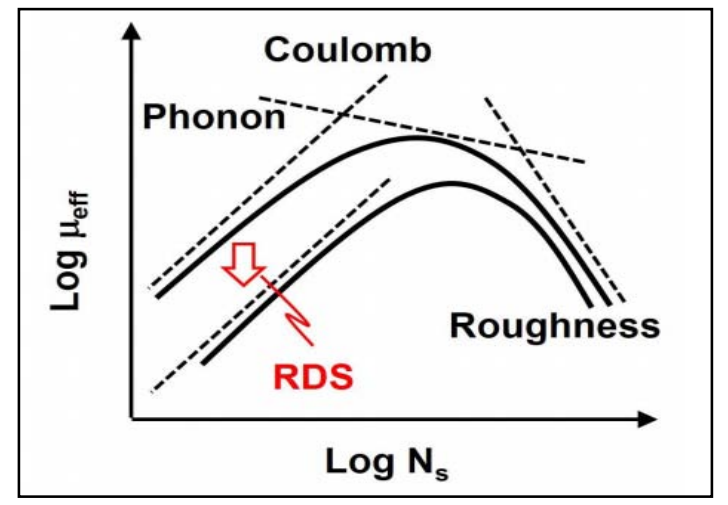

FIG. 6. Schematic of the RDS on electron mobility.

\section{IV.CONCLUSIONS}

In summary, the RCS for mobility degradation of Ge nMOSFET is experimentally investigated, and the electric dipole at $\mathrm{Al}_{2} \mathrm{O}_{3} / \mathrm{GeO}_{\mathrm{x}}$ interface plays a significant role on mobility degradation. Our findings indicate that understanding of the interface dipole at $\mathrm{Al}_{2} \mathrm{O}_{3} / \mathrm{GeO}_{\mathrm{x}}$ is critically important for mobility analysis. Engineering of this interface is a key for both mobility improvement and $\mathrm{V}_{\mathrm{FB}}$ tuning. The discovery of this new scattering mechanism in Ge based MOSFETs is helpful for further improvement of mobility and device performance.

\section{ACKNOWLEDGEMENTS}

This work was financially supported by National Natural Science Foundation of China (Nos. 61504163, 61574168, 61504001) and the Beijing Municipal Natural Science Foundation (No.4162023).

\section{REFERENCES}

[1] S. Ogawa et al., J Applied Physics 118 (23), 235704 (2015).

[2] C. Lu et al., Applied Physics Letters 107(7), 072904 (2015).

[3] T. Hosoi et al., Applied Physics Letters 107(25), 252104 (2015).

[4] R. Asahara et al., Applied Physics Letters 106 (23), 233503(2015).

[5] T. Kanashima et al., J Applied Physics 118 (22), 225302 (2015).

[6] C. H. Lee et al., presented at the Symposium on VLSI Technology, 2013, p.28.

[7] R. Zhang et al., presented at the Symposium onVLSI Technology, 2013, p.26.

[8] R. Zhang et al., Applied Physics Letters 98 (11), 112902 (2011).

[9] Y. X. Zheng et al., IEEE Electron Device Letters, 36 (9), 881883(2015).

[10] S.-i. Saito et al., J Applied Physics 98 (11), 113706 (2005).

[11]11.D. Kuzum et al., IEEE Transactions on Electron Devices 58 (1),5966 (2011).

[12] R. Zhang et al., IEEE Transactions on Electron Devices 60 (3), 927934 (2013).

[13]C. H. Lee et al., presented at the Symposium on VLSI Technology, 2014, p.1.

[14]C. H. Lee et al., presented at the IEEE International Electron Devices Meeting, 2014, p.32.5.1.

[15] Y. Nian et al., IEEE Transactions on Electron Devices, 47 (2), 440-447 (2000).

[16] S. Barraud et al., J Applied Physics 104 (7), 073725 (2008).

[17]D. Casterman and M. M. De Souza, Journal of Applied Physics 107 (6), 063706 (2010).

[18]D. Esseni and A. Abramo, IEEE Transactions on Electron Devices, 50(7), 1665-1674 (2003).

[19] X. Yu et al., Microelectronic Engineering 147, 196-200 (2015).

[20]R. Zhang et al., IEEE Transactions on Electron Devices 59 (2), 335341 (2012).

[21]X. Wang et al., Applied Surface Science 357, Part B, 1857-1862 (2015).

[22] N. Taoka et al., Journal of Applied Physics 108 (10), 104511 (2010).

[23] S. Takagi et al., IEEE Transactions on Electron Devices 41 (12), 23572362 (1994).

[24] X. Wang et al., Applied Physics Letters 97 (6), 062901 (2010).

[25] S. Deng et al., Journal of The Electrochemical Society 155 (2), G33G38 (2008).

[26]27. W. Monch, Semiconductor Surfaces and Interfaces, Springer, p. 92(2001).

[27] 28. S. G. Louie et al., Physical Review B 15(4), 2154-2162 (1977).

[28]29. D. Jena et al., Journal of Applied Physics 88(8), 4734-4738 (2000).

[29]30. H. Ota et al., presented at the IEEE International Electron Devices Meeting, 2007, p.6. 